\title{
Expression of NMDA receptor and microRNA-219 in rats submitted to cerebral ischemia associated with alcoholism
}

\author{
Expressão do receptor de NMDA e do microRNA-129 em ratos submetidos à isquemia \\ cerebral associada ao alcoolismo
}

Cristiane lozzi Silva ${ }^{1}$, Paulo Cézar Novais ${ }^{2}$, Andressa Romualdo Rodrigues ${ }^{1}$, Camila A.M. Carvalho ${ }^{3}$, Benedicto Oscar Colli', Carlos Gilberto Carlotti Jr.', Luís Fernando Tirapelli', Daniela P.C. Tirapelli ${ }^{1}$

\begin{abstract}
Alcohol consumption aggravates injuries caused by ischemia. Many molecular mechanisms are involved in the pathophysiology of cerebral ischemia, including neurotransmitter expression, which is regulated by microRNAs. Objective: To evaluate the microRNA-219 and NMDA expression in brain tissue and blood of animals subjected to cerebral ischemia associated with alcoholism. Methods: Fifty Wistar rats were divided into groups: control, sham, ischemic, alcoholic, and ischemic plus alcoholic. The expression of microRNA-219 and NMDA were analyzed by real-time PCR. Results: When compared to the control group, the microRNA-219 in brain tissue was less expressed in the ischemic, alcoholic, and ischemic plus alcoholic groups. In the blood, this microRNA had lower expression in alcoholic and ischemic plus alcoholic groups. In the brain tissue the NMDA gene expression was greater in the ischemic, alcoholic, and ischemic plus alcoholic groups. Conclusion: A possible modulation of NMDA by microRNA-219 was observed with an inverse correlation between them.
\end{abstract}

Keywords: brain ischemia; alcoholism; N-Methylaspartate; microRNAs.

\begin{abstract}
RESUMO
Algumas condições podem agravar os danos causados pelo processo isquêmico, tais como o consumo de álcool, e diversos mecanismos moleculares que estão envolvidos na fisiopatologia da isquemia cerebral, incluindo a expressão de neurotransmissores, e estes podem estar regulados por microRNAs. Objetivo: Avaliar a expressão de NMDA e do microRNA-219 no tecido cerebral e no sangue de animais submetidos à isquemia cerebral associada ao alcoolismo. Métodos: 50 ratos Wistar foram divididos em: controle, sham, isquêmico, alcoólico e isquêmico mais alcoólico. A expressão de microRNA-219 e de NMDA foram analisadas por PCR em tempo real. Resultados: Quando comparado com o grupo controle, o microRNA-219 no tecido cerebral foi menos expresso nos grupos isquêmico, alcoólico e associado. No sangue, este microRNA teve menor expressão no grupo alcoólico e no associado. Em relação à expressão do gene do NMDA, em tecido cerebral foi maior nos grupos isquêmico, alcoólico e no associado. Conclusão: Uma possível modulação de NMDA pelo microRNA-219 foi observada, com uma correlação inversa entre eles.
\end{abstract}

Palavras-chave: isquemia encefálica; alcoolismo; N-Metilaspartato; microRNAs.

Cerebral ischemia is the third cause of death after cardiovascular diseases and cancer in Brazil, according to a survey of the Brazilian Society of Neurology in 2000, and the major cause of permanent sequelae that generate disability'. Some studies show that the incidence of stroke in the United States affects between 500,000 and 750,000 people, mainly over 65 years of age, annually ${ }^{2}$. There are several important factors for cerebral ischemia risks, among them hypertension, smoking, physical inactivity and obesity ${ }^{3}$.
Several studies have evaluated the role of neurotransmitters in experimental cerebral ischemia associated with harmful agents such as alcohol. It has long been accepted that excessive use of alcohol can cause structural and functional abnormalities of the brain and other organs. In the brain, these abnormalities have been demonstrated clinically, with imaging techniques and histopathology ${ }^{4}$. The role of alcohol as a risk factor for stroke is not clear. A primary intracerebral hemorrhage is

\footnotetext{
'Universidade de São Paulo, Departamento de Cirurgia e Anatomia, Ribeirão Preto SP, Brasil;

Universidade de Marília, Departamento de Odontologia, Marília SP, Brasil;

${ }^{3}$ Universidade Federal de Alagoas, Instituto de Ciências Biológicas e da Saúde, Maceió AL, Brasil.

Correspondence: Daniela P. C. Tirapelli; Faculdade de Medicina de Ribeirão Preto; Av dos Bandeirantes, 3900; $14049-900$ Ribeirão Preto SP, Brasil; E-mail:.daniela@fmrp.usp.br

Conflict of interest: There is no conflict of interest to declare.

Received 22 July 2016; Accepted 10 October 2016.
} 
strongly related to alcohol abuse, which is also involved in subarachnoid hemorrhage ${ }^{5}$.

More recently, many morphological, biochemical and molecular studies have aimed at examining the change that alcohol promotes in the nervous system. Sathyan, Miranda and Golden have shown that high doses of ethanol suppress the expression of specific microRNAs (miRNA) during cortical neurogenesis (miR-21, miR-335, miR-9 and miR-153) Data using microarrays indicated that of these, miR-21 and miR-335 were the most highly suppressed, as miR-21 occurs through mechanisms of neurotransmitter action via, for example, a GABA receptor-dependent mechanism. The miRNA sensitivity to ethanol behaves agonistically or antagonistically towards the survival and growth of the neuroepithelium, and the coordinated suppression of miR-21 and miR-335 explains why ethanol leads to the proliferation rather than the death of precursors of the fetal cerebral cortex. These data indicate that the miRNA sensitivity to ethanol controls important genes during development. MicroRNAs are a class of small RNA that negatively regulate gene expression at a post-transcriptional level. The discovery of small noncoding molecules has improved our understanding of the mechanism of gene expression regulation ${ }^{7}$. MicroRNAs contain 18-25 nucleotides that regulate the stability or efficiency of the RNA transduction messenger (mRNA) ${ }^{8}$. Approximately $40 \%$ to $50 \%$ of mammalian mRNA can be regulated at the level of miRNA translation. In mammals, specific miRNAs control development, neuronal cell fate and apoptosis9.

Some studies have shown the potential of miRNAs as novel biomarkers of vascular injury and disease. The expression profile of miRNAs in rats with cerebral ischemia shows significant changes in several miRNAs that were highly expressed in ischemic brains, which were detected in blood samples ${ }^{10}$.

Little is known about the role of miRNAs in the case of cerebral ischemia especially as regards the glutamate neurotransmitter. The changes in the expression profile of this neurotransmitter in alcoholism are also relevant, as there is a public health concern of $20 \%$ of the population with somatic and psychic complications, with profound social repercussions. Therefore, not only it is our goal in this study, but it is of paramount importance that we clarify the role of miRNAs in the mechanisms involved in the imbalance of the glutamatergic neurotransmission in brain ischemia as well as its association with the possible damage caused by chronic alcohol consumption, which generates a broad impact on society globally.

\section{METHODS}

\section{General procedures}

The experiments were carried out according to the Ethical Principles for Experimental Animals and the study was approved by the Animal Experimentation Committee of the Medical School of Ribeirão Preto - University of São Paulo. Fifty adult male rats (Rattusnorvegicus) weighing 280-310g were used. The animals were randomly divided into five experimental groups: control: 10 animals sacrificed without being submitted to the surgical procedure; sham: 10 control animals submitted to complete simulation of the surgical procedure but without obstruction of the middle cerebral artery (MCA) and then sacrificed; ischemic: 10 animals submitted to focal ischemia by occlusion of the MCA for 90 minutes followed by reperfusion for 48 hours, and then sacrificed; alcoholic: 10 animals received ethanol diluted to $20 \%$ in water for four weeks and then they were sacrificed; and, ischemic and alcoholic: 10 animals subjected to the same treatment as the alcoholic group and after four weeks, were submitted to focal cerebral ischemia for 90 minutes followed by reperfusion for 48 hours. Weekly measurements of the weight of the animals were taken in the different study groups.

The preparation of these experimental groups included conditioning them to a brief period of gradual adaptation to the consumption of ethanol, which consisted of supplying ethanol diluted in water, changing its concentration gradually in weekly increasing doses of 5\%,10\% and $20 \%$. The initiation of the experimental phase was at the beginning of the third week of treatment.

All animals were partially anesthetized by halothane inhalation and intubated with an orotracheal cannula. On two occasions during the ischemic period, arterial blood samples were collected for the determination of glycemia, $\mathrm{paCO}_{2}$, $\mathrm{paO}_{2}$ and $\mathrm{pH}$. An MCA occlusion was created through the external carotid artery, which was ligated cranially and sectioned for the retrograde introduction of a $2.5 \mathrm{~cm}$ long obstructive 4-0 mononylon suture with one end thickened with silicone over a section of $5 \mathrm{~mm}$. The suture was introduced until it reached the common carotid artery and then cranially progressed through the internal carotid artery to reach and obstruct the MCA.

After the period of ischemia, we removed the obstructing thread, replacing the temporary clampon in the common carotid artery to prevent the flow of blood and in the internal carotid artery to prevent the blood reflux. The proximal stump of the external carotid artery was permanently connected and the temporary clamps were removed. Then, the skin and subcutaneous tissues were closed in animals from the ischemic, and ischemic and alcoholic groups.

\section{Analysis of microRNA-219 and NMDA gene expression (tissue and serum)}

For the analysis of gene expression, 10 animals were used per group. A fragment was obtained from each animal and $1 \mathrm{ml}$ of blood was collected at a single moment in the four study groups.

Total RNA was extracted with Trizol reagent (Applied Biossystems, USA) according to the manufacture's instructions. To verify the integrity of the RNA obtained, each sample was subjected to electrophoresis on agarose gel $1 \%$ RNA and put through the spectrophotometer that provides the 
RNA concentration in a sample of 1 to $2 \mu$ l. In addition to the concentration, this device provides us with values relating to the integrity of the samples (260/280 ratio). The ideal range to be obtained is 1.7 to 1.9 .

To prepare the real-time polymerase chain reaction (PCR), reverse transcription of RNA samples was performed using the High-Capacity cDNA kit (Applied Biossystems, USA). The cDNA was amplified with quantitative real-time PCR using the TaqMan Master Mix (Applied Biosystems) for miRNA reaction.

Endogenous control for the reaction of the miRNA and the gene, was through the use of U6 and GAPDH, respectively. All reactions were carried out in duplicate and analyzed with the 7500 Sequence Detection System apparatus (Applied Biosystems).

\section{Immunohistochemical analysis}

The brain tissue samples collected were stained for histopathological and morphometric analyses, both by Trichrome Masson's stain, and immunohistochemistry for protein expression of NMDA.

The coronal sections of brain tissue $(3 \mu \mathrm{m})$ were fixed by immersion in $4 \%$ paraformaldehyde and embedded in paraffin and subjected to immunohistochemical analysis by the avidin-biotin-peroxidase method, and the brain tissue was incubated with NMDA antibodies.

The reading of the NMDA protein expression was performed in five animals of each group and two parameters were analyzed: a) Percentage of positively stained cells (neurons and glia cells) in area 1 (dorsolateral cortex) and area 2 (lateral cortex), both of the left cerebral hemisphere; b) Percentage of positively stained cells (neurons and glia cells) in the striatum (striatum - area 3) of the left cerebral hemisphere. In both parameters, the percentage of positive cells was calculated, from the count of the total number of positive and negative cells.

\section{Statistical analysis}

Data concerning the miRNA, gene and protein expression and morphometric analysis in the various groups were analyzed statistically by Kruskal-Wallis test followed by the Bonferroni post-test using the GraphPad Prism software (GraphPad Software, San Diego, CA, USA). The level of significance was set at $\mathrm{p}<0.05$ for two-tailed tests.

\section{RESULTS}

The miR-219 in brain tissue was less expressed in the groups submitted to cerebral ischemia, alcoholism, and the alcoholic and cerebral ischemia groups compared to the control group (Figure 1). However, the expression of miR-219 in the blood was lower only in the alcoholic group and in the alcoholic and cerebral ischemia group when compared to the control group (Figure 2).
The gene expression of NMDA neurotransmitter was greater in the brain tissue of animals with cerebral ischemia, alcoholism, and the alcoholic and cerebral ischemia groups compared to the control group (Figure 3). The protein expression of the NMDA neurotransmitter in the brain tissue was greater in the mice in the cerebral ischemia, alcoholism, and the alcoholic and cerebral ischemia groups when compared to the control group (Figure 4). Cytoplasmic positive staining for NMDA protein was observed in the three regions analyzed (dorsolateral cortex, striatum and lateral cortex of the ischemic focus in the nerve tissue of the left cerebral hemisphere) in all groups. Figure 5 shows the comparison of the expression of this protein among the four groups.

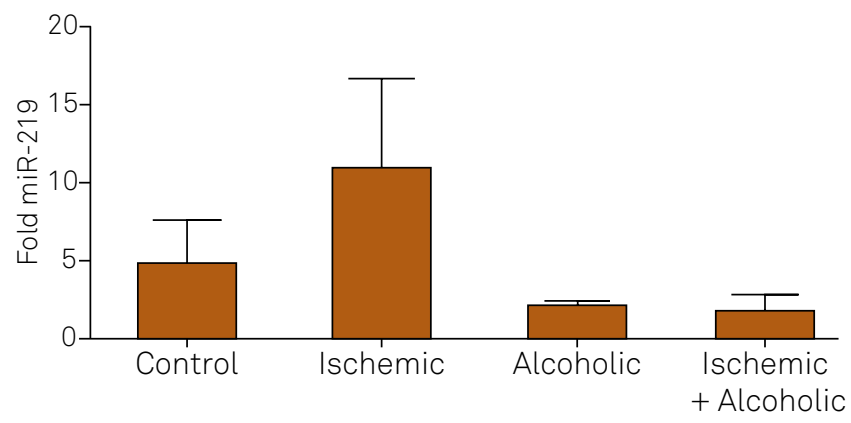

Figure 1. Representation average ( \pm standard deviation) of miR-219 in the blood among the groups ( $p=0.0461$, Kruskal-Wallis).

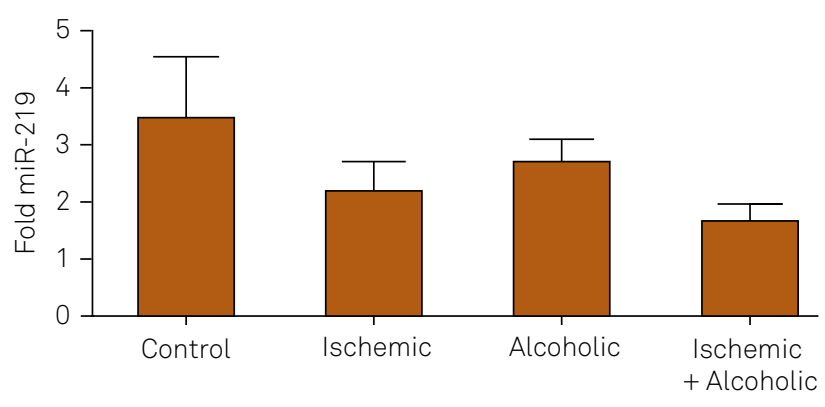

Figure 2. Representation average ( \pm standard deviation) of miR-219 in brain tissue among the groups ( $p=0.0373$, Kruskal-Wallis).

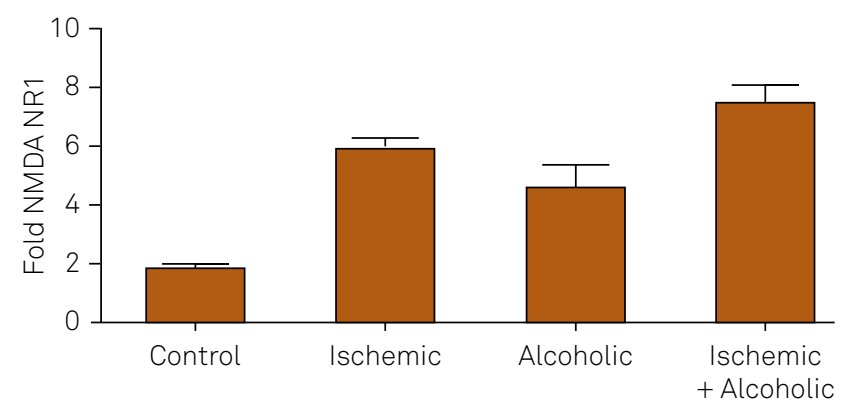

Figure 3. Representation average ( \pm standard deviation) of gene expression of NMDA receptor NR1 in the groups studied $(p=0.0211$, Kruskal-Wallis test $)$. 


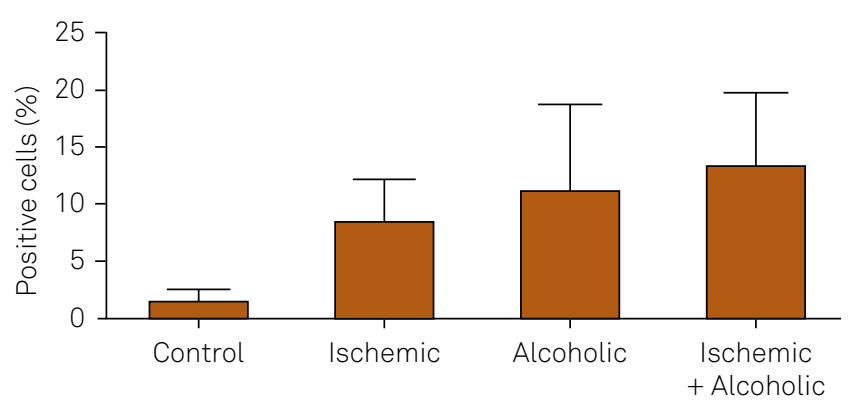

Figure 4. Representation of the average ( \pm standard deviation) of the protein expression of NMDA receptor NR1 in the groups $(p=0.0289$, Kruskal-Wallis test $)$.
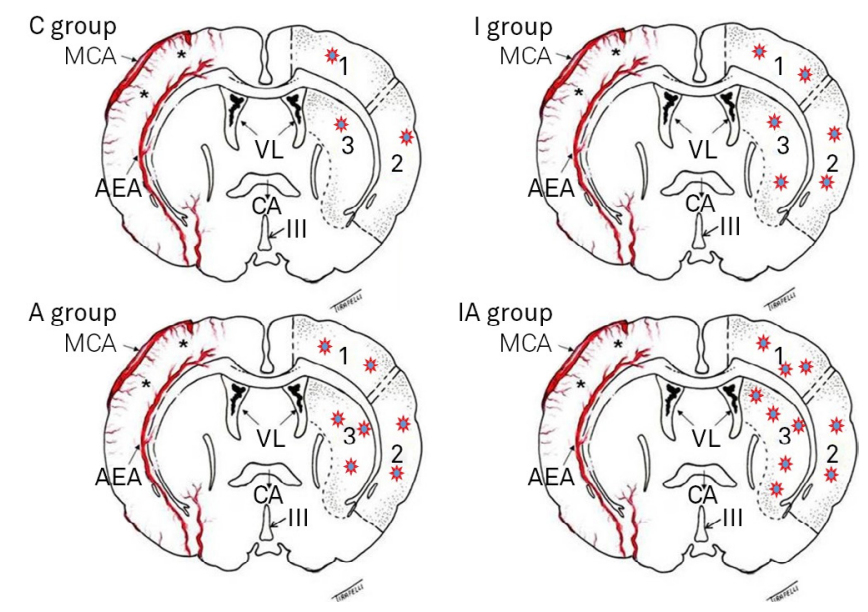

Figure 5. Protein expression NMDA. Illustration of coronal sections of the brain the four groups showing in the left cerebral hemisphere, and from the three regions evaluated, diffuse distribution in protein expression of NMDA (red stars). Note: a higher expression in the striatum of the IA group. (Tirapelli, ${ }^{23}$, with permission). C: control; A: alcoholic; I: ischemic; IA: ischemic and alcoholic.

\section{DISCUSSION}

This work aimed at evaluating the possible modulation of the NMDA receptor NR1 by the action of miR-219 in animals subjected to focal cerebral ischemia with or without an alcohol abuse model.

Seeking to clarify the molecular mechanisms involved in controlling the expression of NMDA receptors, the literature has highlighted the characterization of the expression profile of miRNAs in the modulation of neurotransmitters. In a study with rats subjected to cerebral ischemia by occlusion of the MCA and reperfusion for 24 and 48 hours, Jeyaseelan, Lim, Armugam performed a comprehensive analysis of the expression profile of the miRNA technique for large-scale analysis of microarrays, followed by the validation of the selected real-time PCR in the blood of animals as well as in ischemic tissue miRNAs ${ }^{9}$. Three groups of miRNAs were identified in the blood of animals. The first miRNAs were differentially expressed only in the 24-hour reperfusion brain samples, and some others overexpressed and underexpressed. The second group was comprised of miRNAs that changed their expression levels only after 48 hours of reperfusion. The third group was comprised of miRNAs that had different levels of expression in both periods of reperfusion ${ }^{10}$.

Dharap et al. analyzed the role of miRNAs in the modulation of reperfusion in animals subjected to cerebral ischemia by occlusion of the MCA. The authors analyzed 238 miRNAs, of which eight overexpressed and 12 underexpressed ${ }^{11}$. It was observed that $20 \%$ of the miRNAs analyzed ( 47 of 238 ) show alterations over a period of reperfusion. Therefore, the study indicated that cerebral ischemia in the expression of miRNAs varies according to the time of reperfusion ${ }^{11}$. Kye et al. ${ }^{12}$ analyzed the expression of 187 miRNAs by real-time PCR in embryonic cultures of hippocampal neurons. The authors evaluated the mechanisms involved in the regulation of miRNAs after the intraperitoneal administration of an antagonist of NMDA acid receptors (CPP) and found 32 miRNAs had changed.

In our work we analyzed the expression of miR-219 in ischemic brain tissue, which underexpressed in the group subjected to cerebral ischemia, the alcoholism group, and the alcoholic and cerebral ischemia group. We also observed an inverse correlation between the pattern of protein expression of NMDA receptor NR1 and tissue expression of miR-219.

Due to the specificity of miR-219 in brain tissue, other studies in the current literature have demonstrated the role of this miRNA in cerebral ischemia. Among them, Pai et al., who, after silencing Ago2 protein and RISC complex in rat long-term potentiation found by real-time PCR, discovered that the regulation of expression levels of several miRNAs, including the miR-219, was totally dependent on the NMDA receptor activation during long-term potentiation ${ }^{13}$. In another study, Kocerba et al. analyzed the expression of miR-219, a brain-specific miRNA, after pharmacological intervention (administration of dizocilpine) or genetic disruption (NR1 hypomorphism). The authors found that miR-219 quickly responded to changes in NMDA receptor signaling by two types of interventions ${ }^{14}$. Winbrad et al. have also demonstrated the regulation of the NMDA receptor by miR-219. The authors found that the activation of NMDA receptors during long-term potentiation leads to a decreased expression of miR-219, among other miRNAs ${ }^{15}$.

MicroRNAs have also been highlighted as biomarkers associated with various diseases, among which are cerebral ischemia and alcoholism. In this regard, Liu et al. ${ }^{16}$ analyzed the expression profile of miRNAs in global cerebral tissue and in the blood of animals undergoing the following models of brain diseases: cerebral ischemia, cerebral hemorrhage induced by kainite, and epilepsy. Many overexpressed or underexpressed miRNAs were found in each experimental condition. The authors describe functions associated with common molecular mechanisms in brain tissue and blood as cell cycle, cell death, cell morphology and development of the organism, and they even suggested, according to the results, 
that some diseases are brain responses, similar in both brain tissue and blood.

In this work, when we analyzed miR-219 in the blood of animals, we found that levels of expression of miRNAs were reduced in the group submitted to alcoholism, and in the alcoholic and cerebral ischemia group when compared to the control group. This suggests that this miRNA may have an important role as biomarker.

Some studies have already demonstrated the role of miRNAs as biomarkers in humans. The study by Zeng et al. examined the expression of miR-210 in 112 patients with cerebral ischemia and compared it with 60 control subjects. The miR-210 showed $88.3 \%$ sensitivity and was a good candidate for a biomarker. This study also evaluated the expression of miR-210 in blood and in the tissue of mice subjected to cerebral ischemia, and a correlation between blood and tissue was observed in the expression levels of miR-210. Another study in humans has also analyzed the expression of miRNAs miR-21, miR-221 and miR-145 in the serum of 167 patients with cerebral ischemia. The patients had high levels of expression of miR-21 and miR-221 and low expression levels of miR-145 ${ }^{17}$.

The brain is one of the organs most affected by the action of alcohol on the body ${ }^{18}$. However, which events are associated with the damage of brain tissue due to alcohol consumption are still not clearly established. Therefore, many studies have attempted to establish the molecular mechanism involved in the cerebral action of alcohol, among them Zhao et al., who evaluated the influence of the amount/dose of ethanol consumption in animals subjected to cerebral ischemia, by occlusion of the middle cerebral artery for two hours followed by reperfusion for 24 hours. The authors noted an increase in the volume of infarcted region in doses of $6.4 \%$ ethanol, and found increased expression of NR1 NMDA receptor at the same concentration of $6.4 \%$. However, at low doses there was a $1 \%$ reduction in the volume of the infarct region suggesting the neuroprotective effect of ethanol in low concentrations ${ }^{19}$.

The majority of excitatory synapses in the central nervous system are mediated by NMDA receptors and several studies have shown that chronic alcoholism exposure increases the expression of the NR1 and NR2B receptors ${ }^{18}$. Trudell et al. reported evidence that the action of ethanol in the subunits of the NMDA and $\mathrm{GABA}_{\mathrm{A}}$ receptors is responsible for behavioral effects, one of them, for example, through the activation of Fyn protein, a modulator of the NMDA receptor in specific regions of the brain, which leads to an increase in NMDA receptor signaling, facilitating the increase in the consumption as well as consumption relapse ${ }^{20}$.

Gorini, Nunez, and Mayfield analyzed the global expression profile of miRNAs in the cerebral cortex and midbrain of mice submitted to chronic intermittent alcohol, and found different levels of expression in the brain regions studied. These data demonstrate that the changes caused by alcohol in the brain tissue, as regards the expression profile of the evaluated miRNA region, is very important ${ }^{21}$. In another study, also by global analysis of expression profiling by microarray technique, Mantha and Singh analyzed the exposure to prenatal ethanol in adult mice and found 20 miRNAs differentially expressed, and subsequently validated the miR-302c. Further studies are needed to clarify the interaction between the pathophysiology of cerebral ischemia associated with alcoholism ${ }^{22}$. Based on our findings and literature, other miRNAs, with different periods of reperfusion, need to be evaluated.

\section{References}

1. Lotufo PA. Mortalidade pela doença cerebrovascular no Brasil. Rev Bras Hipertens. 2000;7(4):387-91.

2. Kim MW, Bang MS, Han TR, Ko YJ, Yoon BW, Kim JH et al. Exercise increased BDNF and trkB in the contralateral hemisphere of the ischemic rat brain. Brain Res. 2005;1052(1):16-21. doi:10.1016/j.brainres.2005.05.070

3. Bronner LL, Kanter DS, Manson JE. Primary prevention of stroke. N Engl J Med. 1995;333(21):1392-400. doi:10.1056/NEJM199511233332106

4. Harper C. The neuropathology of alcohol-related brain damage. Alcohol. 2009;44(2):136-40. doi:10.1093/alcalc/agn102

5. Ohsawa M, Tanno K. Conflicting effect of alcohol on cardiovascular risk: a clue to understand the different etiologies of coronary artery disease, stroke and peripheral artery disease. Hypertens Res. 2013;36(1):16-8. doi:10.1038/hr.2012.152

6. Sathyan P, Golden HB, Miranda RC. Competing interactions between micro-RNAs determine neural progenitor survival and proliferation after ethanol exposure: evidence from an ex vivo model of the fetal cerebral cortical neuroepithelium. J Neurosci. 2007;27(32):8546-57. doi:10.1523/JNEUROSCI.1269-07.2007

7. Conti A, Aguennouz M, La Torre D, Tomasello C, Cardali S, Angileri FF et al. miR-21 and 221 upregulation and miR-181b downregulation in human grade II-IV astrocytic tumors. J Neurooncol. 2009;93(3):325-32. doi:10.1007/s11060-009-9797-4
8. Mendell JT. MicroRNAs: critical regulators of development, cellular physiology and malignancy. Cell Cycle. 2005;4(9):1179-84. doi:10.4161/cc.4.9.2032

9. Jeyaseelan K, Lim KY, Armugam A. MicroRNA expression in the blood and brain of rats subjected to transient focal ischemia by middle cerebral artery occlusion. Stroke. 2008;39(3):959-66. doi:10.1161/STROKEAHA.107.500736

10. Saugstad JA. MicroRNAs as effectors of brain function with roles in ischemia and injury, neuroprotection, and neurodegeneration. J Cereb Blood Flow Metab. 2010;30(9):1564-76. doi:10.1038/jcbfm.2010.101

11. Dharap A, Bowen K, Place R, Li LC, Vemuganti R. Transient focal ischemia induces extensive temporal changes in rat cerebral microRNAome. J Cereb Blood Flow Metab. 2009;29(4):675-87. doi:10.1038/jcbfm.2008.157

12. Kye MJ, Neveu P, Lee YS, Zhou M, Steen JA, Sahin M et al. NMDA mediated contextual conditioning changes miRNA expression. PLoS One. 2011;6(9):e24682. doi:10.1371/journal.pone.0024682

13. Pai B, Siripornmongcolchai T, Berentsen B, Pakzad A, Vieuille C, Pallesen $S$ et al. NMDA receptor-dependent regulation of miRNA expression and association with Argonaute during LTP in vivo. Front Cell Neurosci. 2014;7:285. doi:10.3389/fncel.2013.00285 
14. Kocerha J, Faghihi MA, Lopez-Toledano MA, Huang J, Ramsey AJ, Caron MG et al. MicroRNA-219 modulates NMDA receptor-mediated neurobehavioral dysfunction. Proc Natl Acad Sci USA. 2009;106(9):3507-12. doi:10.1073/pnas.0805854106

15. Wibrand K, Panja D, Tiron A, Ofte ML, Skaftnesmo KO, Lee CS et al. Differential regulation of mature and precursor microRNA expression by NMDA and metabotropic glutamate receptor activation during LTP in the adult dentate gyrus in vivo. Eur J Neurosci. 2010;31(4):636-45. doi:10.1111/j.1460-9568.2010.07112.x

16. Liu DZ, Tian Y, Ander BP, Xu H, Stamova BS, Zhan X et al. Brain and blood microRNA expression profiling of ischemic stroke, intracerebral hemorrhage, and kainate seizures.J Cereb Blood Flow Metab. 2010;30(1):92-101. doi:10.1038/jcbfm.2009.186

17. Zeng L, Liu J, Wang Y, Wang L, Weng S, Tang Y et al. MicroRNA-210 as a novel blood biomarker in acute cerebral ischemia. Front Biosci (Elite Ed). 2011;3:1265-72. doi:10.2741/330

18. Chandrasekar R. Alcohol and NMDA receptor: current research and future direction. Front Mol Neurosci. 2013;6:14. doi:10.3389/fnmol.2013.00014
19. Zhao H, Mayhan WG, Arrick DM, Xiong W, Sun H. Dose-related influence of chronic alcohol consumption on cerebral ischemia/reperfusion injury. Alcohol Clin Exp Res. 2011;35(7):1265-9. doi:10.1111/j.1530-0277.2011.01461.x

20. Trudell JR, Messing RO, Mayfield J, Harris RA. Alcohol dependence: molecular and behavioral evidence. Trends Pharmacol Sci. 2014;35(7):317-23. doi:10.1016/j.tips.2014.04.009

21. Gorini G, Nunez YO, Mayfield RD. Integration of miRNA and protein profiling reveals coordinated neuroadaptations in the alcohol-dependent mouse brain. PLoS One. 2013;8(12):e82565. doi:10.1371/journal.pone.0082565

22. Mantha K, Laufer BI, Singh SM. Molecular changes during neurodevelopment following second-trimester binge ethanol exposure in a mouse model of fetal alcohol spectrum disorder: from immediate effects to long-term adaptation. Dev Neurosci. 2014;36(1):29-43. doi:10.1159/000357496

23. Tirapelli DPC, Carlotti Jr CG, Leite JP, Lizarte FS, Tirapelli LF, Colli BOC. Analysis of the NMDA in focal cerebral ischemia inrats. Int $\mathrm{J} \mathrm{Morphol.}$ 2012;30:979-85. doi:10.4067/S0717-95022012000300035 